\title{
Influence of the Master Pattern Angle on Perpendicular Magnetic Contact Printing Characteristics
}

\author{
T. Saito, Y. Sakaguchi, S. Okami, T. Komine, and R. Sugita \\ Ibaraki University, 4-12-1 Nakanarusawa-cho, Hitachi, Ibaraki 316-8511, Japan
}

The influence of the inclination angle of the master pattern on the edge printing characteristics for writing phase servo patterns on perpendicular magnetic recording media was investigated. Even if the master pattern angle is 40 degrees, the printing characteristics are only 10 percent lower than when the angle is 0 degrees. The influence of the inclination angle of the master pattern on the printing characteristics is also small when the bit length is changed. The contribution of the in-plane component of the recording field to magnetization reversal is large in edge printing. Although the perpendicular component of the recording field decreases markedly as the inclination angle of the master pattern increases, edge printing can be used for writing phase servo patterns on slave media.

Key words: magnetic contact printing, perpendicular magnetic recording media, hard disk, phase servo.

\section{マスターパターンの傾きが垂直磁気転写特性に及ぼす影響}

齋藤俊明・坂口雄一・岡見智史・小峰啓史・杉田龍二

茨城大学工学部, 茨城県日立市中成沢町 4-12-1(广316-8511)

\section{1. はじめに}

磁気転写法は, ハードディスク(HD)にサーボ信号を高速, 高精 度かつ安価に書き込む方法として注目されている 1). また, HDの 高記録密度化に伴い，位相サーボ方式を用いたヘッドトラッキン グ技術が検討されている2。

垂直磁気転写法には, 2 通りの方法がある. 膜面に対して垂直に 転写磁場を印加するビット転写と, 膜面に対して平行に転写磁場 を印加するエッジ転写である. 位相サーボパターンの概略図, 及び 実際にHD にエッジ転写する際の装置構成を Fig. 1 に示寸. Fig. 1 において, ディスク半径方向からの位相サーボパターンの傾きを $\theta$ とすると, $\theta$ が $40^{\circ}$ 超える場所が存在する. ビッ卜転写を行う場合 には, 転写磁場を膜面垂直方向に印加するので, 転写特性は $\theta$ こ依 存しない. 一方, エッジ転写を行う場合には, 転写磁場印加方向(ダ ウントラック方向)とマスターパターンのパターン方向との成寸角 が $90^{\circ}$ ではなく, $50^{\circ}$ 以下になる場所が存在するため, マスターパタ ーンの傾きによる転写特性への影響が䀣念される.

以前我々は，拡大モデルを用いて位相サーボに対する垂直磁気 転写特性について報告した ${ }^{3)}$ が, 垂直磁気記録 $\mathrm{HD}$ そのものを用い

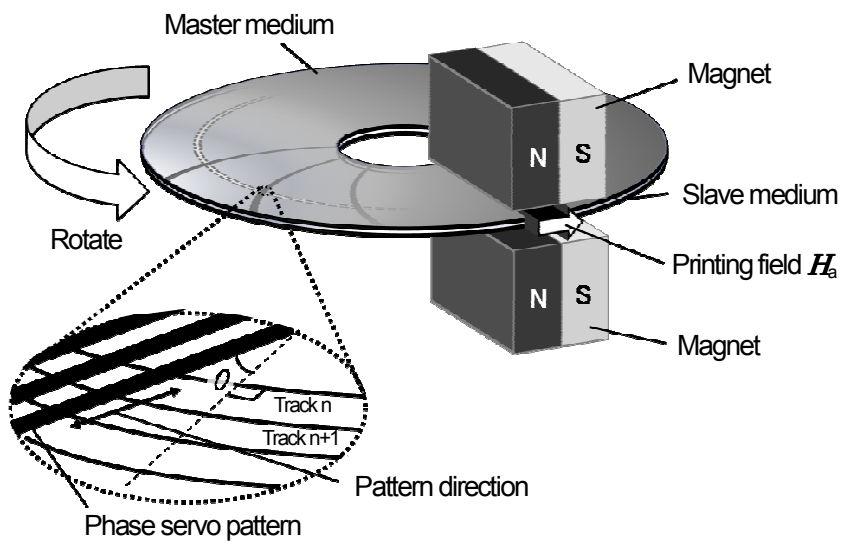

Fig. 1 Schematic of the phase servo pattern and edge printing process for hard disks.
た磁気転写は，まだ検討されていない. 本研究では, エッジ転写に より垂直磁気記録 HD に位相サーボパターンを形成することを目 的として, マスターパターンの傾斜角が垂直磁気転写特性に及ぼ 寸影響について実験及び計算の両面から検討した。

\section{2. 実験及び計算方法}

\section{1 実験方法}

本研究では, マスターパターンのパターン方向が無限大とみな せる, 位相サーボ方式における位相バース卜部のパターンを想定 した. 本実験で用いたマスター媒体の模式四を Fig. 2 に示す. マス ター媒体は, 基板上に $\mathrm{Fe}_{70} \mathrm{Co}_{30}$ 膜 $\left(M_{\mathrm{s}}=1900 \mathrm{emu} / \mathrm{cm}^{3}\right)$ をストライ プ状に形成したものを用いた. ストライプパターンの幅 $L$ 及びパ ターン間隔 $S$ は $100 〜 500 \mathrm{~nm}$ とした. FeCo 膜厚 $\delta$ 唯は $100 \mathrm{~nm}$, トラック幅は約 $7 \mathrm{~mm}$ である. スレーブ媒体には, 保磁力が 4.5 $\mathrm{kOe}$ の市販の垂直磁気記録 HD を用いた。

転写の実験方法を Fig. 3 を用いて説明する. AC 消磁状態のスレ 一ブ媒体にマスター媒体を接触させ， $x$ 軸方向に転写磁場 $H_{\mathrm{a}}$ を印 加した. このとき, 転写磁場により磁化されたマスター媒体からの 磁場と, 転写磁場を重祇合わせた記録磁場が発生し, マスター磁性 膜两側エッジ近傍に発生する磁場の $Z$ 軸方向成分 (垂直成分) によ って, スレーブ媒体が垂直上下方向に磁化される. Fig. 3 に示すよ うに, クロストラック方向 $(y$ 軸方向)からのマスターパターン傾斜 角 $\theta$ が, 位相サーボパターンの傾きに相当するとして, $\theta$ を $0 \sim 40^{\circ}$, 転写磁場 $H_{\mathrm{a}}$ を $4 \sim 12 \mathrm{kOe}$ と変えた. 転写されたスレーブ媒体の 磁化状態は磁気力顕微鏡(MFM)を用いて評価した.

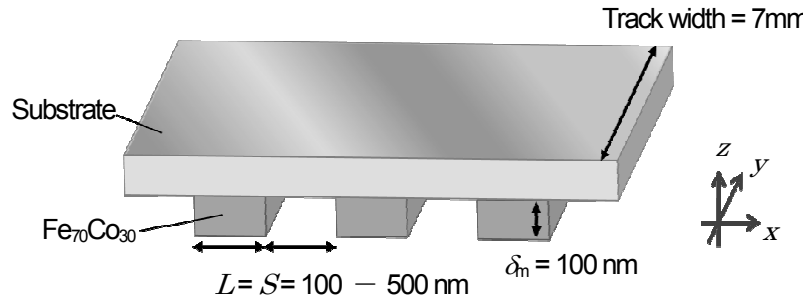

Fig. 2 Schematic of the master medium used in this study. 


\section{3. 結果及び考察}

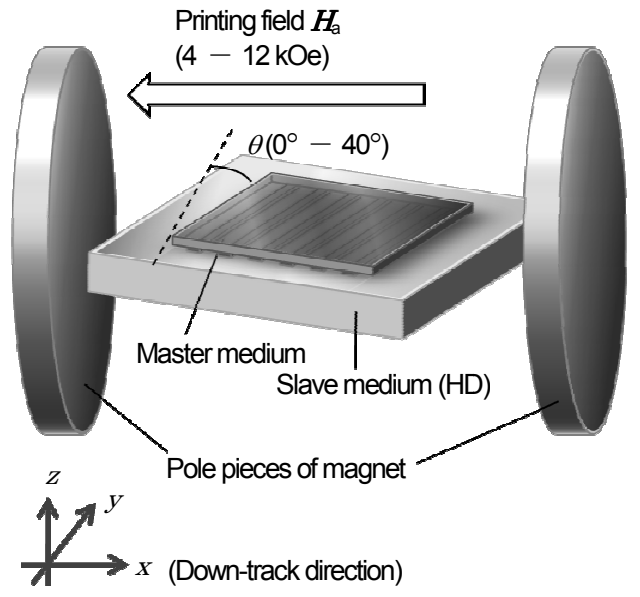

Fig. 3 Edge printing process for writing phase servo patterns in the experiments.

\section{2 計算方法}

位相サーボにおけるスレーブ媒体磁化状態を解析するため, マ イクロマグネティックシミュレーションを行った. 計算モデルを Fig. 4 に示す. 有限要素法により記録層部分に発生する記録磁場分 布を計算し, その磁場分布を用いてマイクロマグネティックシミ ュレーションにより記録層の磁化状態を求めた ${ }^{4), 5)}$. マスター媒体 は, トラック幅無限大の磁性膜がストライプ状に無限に配置され ているパターンを想定し, Fig. 4 に示寸ように $\theta$ を定義して, マス ターパターンの傾きを考慮した. マスター磁性膜の飽和磁化は $1900 \mathrm{emu} / \mathrm{cm}^{3}$ とし, 膜厚 $\delta_{\mathrm{m}}$ を $100 \mathrm{~nm}$, ビット長 $L$ を $250 \mathrm{~nm}$, マ スター媒体とスレー媒体の磁気的スペーシングを $10 \mathrm{~nm}$ とした. 記録層の飽和磁化は $550 \mathrm{emu} / \mathrm{cm}^{3}$, 異方性磁場 $10 \mathrm{kOe}$, 異方性分 散 $1 \mathrm{kOe}$, 膜厚 $\delta_{\mathrm{s}} 15 \mathrm{~nm}$, シード層, 軟磁生裏打ち層(SUL)の膜厚 をそれぞれ $15 \mathrm{~nm}, 200 \mathrm{~nm}$ とした. SULには記録層の鏡像が現れ るものとして，鏡像が作る静磁場を考慮した．また，記録層は $5 \mathrm{~nm} \times 5 \mathrm{~nm} \times 15 \mathrm{~nm}$ の直方体単磁区粒子で構成されているとし, 粒子間交換結合を $2 \times 10^{-7} \mathrm{erg} / \mathrm{cm}$ とした. このときのスレーブ媒 体保磁力は約 $4.2 \mathrm{kOe}$ である. さらに, 実験で得られた MFM出力 と対応させるために, 転写されたスレーブ媒体からの漏れ磁場の 垂直成分をモーメント法により求めた ${ }^{6}$.

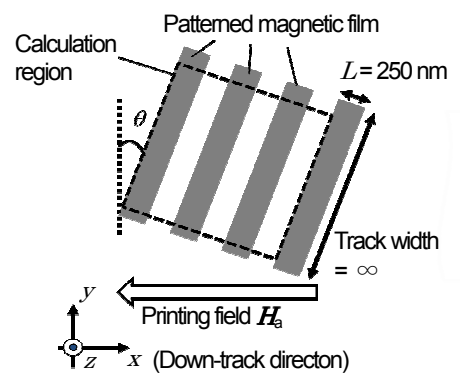

(a) Top view

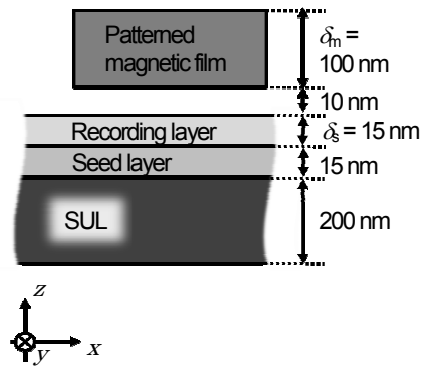

(b) Cross-section view
Fig. 4 Calculation model.

\section{1 転写実験結果}

Lが $250 \mathrm{~nm}$ のマスター媒体を用いて転写された, スレーブ媒体 からの MFM 出力波形を Fig. 5 に示す. Fig. 5 から, $\theta$ を変えても 波形のピークはマスターパターンのエッジ部に現れることがわか る. また, $\theta$ が $0^{\circ}, 40 \circ$ のずれにおいても, 波形はほぼ正弦波になっ た.ここで, Fig. 5(b)に示すように, 波形の p-p 值を $V_{\mathrm{p} p}$ とし, $V_{\mathrm{p}-\mathrm{p}}$ の転写磁場依存性を Fig. 6 に示寸. Fig. 6 から, 転写磁場 $H_{\mathrm{a}}$ が 8 $\mathrm{kOe}$ 付近で $V_{\mathrm{p} p}$ はピークを持ち, $\theta$ を大きくすると $V_{\mathrm{p} p}$ が減少する ことがわかる. しかし，暲 $0^{\circ}$ のきと比べて， $\theta$ が $40^{\circ}$ のきでも $V_{\mathrm{p} p}$ の減少量は $10 \%$ 程度である. これは, 以前に我々が報告した拡 大モデル実験で得られた結果3)とも一致する.

Fig. 7 に, $V_{\mathrm{pp}}$ のビット長依存性を示寸. それぞれのビット長に おいて, 転写磁場は最適転写磁場である $8 \mathrm{kOe}$ とした. Fig. 7 から, ビット長が $100 \mathrm{~nm}$ になると, $250 \mathrm{~nm}$ に比べ $V_{\mathrm{pp}}$ は減少するが, $V_{\mathrm{p} p}$ のマスターパターン傾斜角依存性は同様の傾向を示し, $\theta$ が変 わっても $V_{\mathrm{p} p}$ は $10 \%$ 程度しか劣化していない. また, エッジ転写の $\mathrm{S} / \mathrm{N}$ は, サーボトラックライタ(STW)記録以上であることが報告 されており 1), パターンが 40 程度傾斜しても, サーボ信号として の十分な品質が確保されるものと推測される.

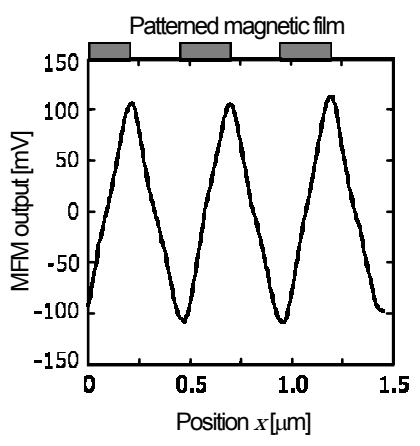

(a) $\theta=0^{\circ}$

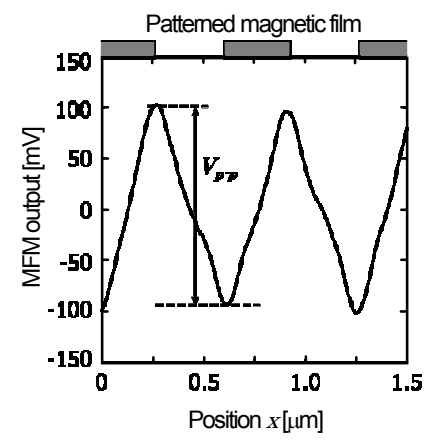

(b) $\theta=40^{\circ}$
Fig. $5 \mathrm{MFM}$ output waveforms from edge printed media with inclination angles of (a) $\theta=0^{\circ}$ and (b) $\theta=40^{\circ}$.

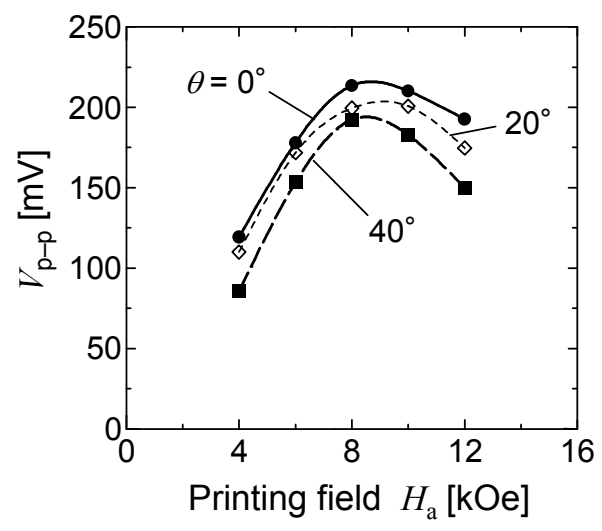

Fig. 6 Dependence of the peak-to-peak value of the MFM output on the printing field in edge printing with various inclination angles. 


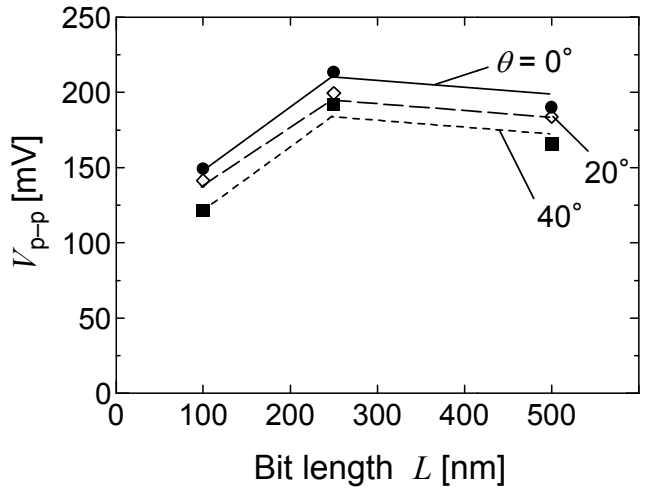

Fig. 7 Dependence of the peak-to-peak value of the MFM output on the bit length in edge printing with various inclination angles.

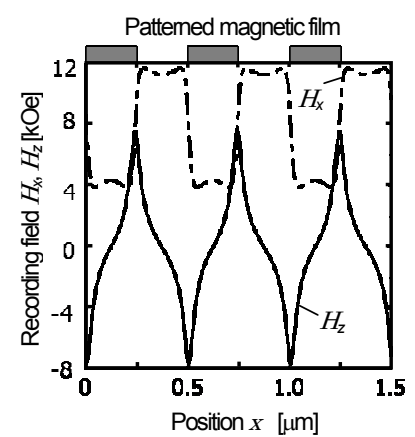

(a) $\theta=0^{\circ}$

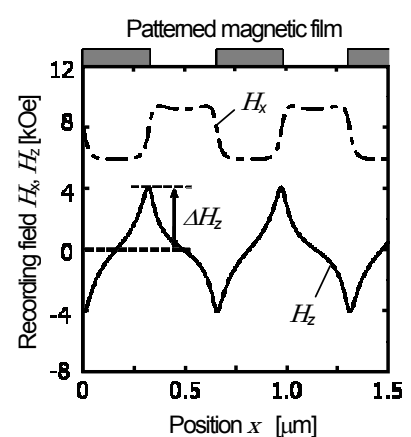

(b) $\theta=40^{\circ}$
Fig. 8 Calculated recording field distributions in edge printing with (a) $\theta=0^{\circ}$ and (b) $\theta=40^{\circ}$.

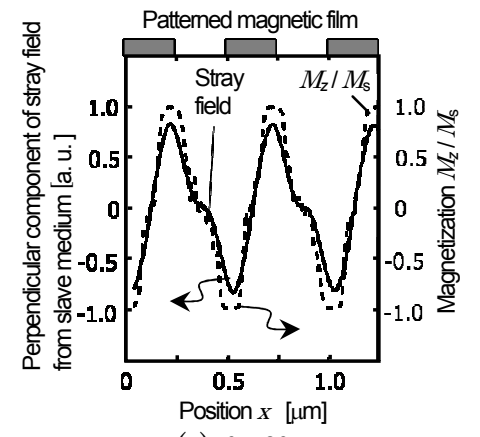

(a) $\theta=0^{\circ}$

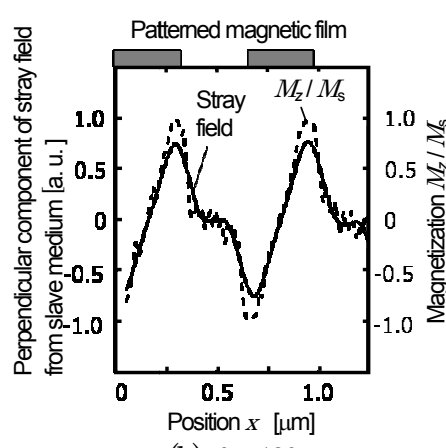

(b) $\theta=40^{\circ}$
Fig. 9 Calculated magnetization and perpendicular component of stray field from slave medium distributions of edge printed media with (a) $\theta=0^{\circ}$ and (b) $\theta=40^{\circ}$.

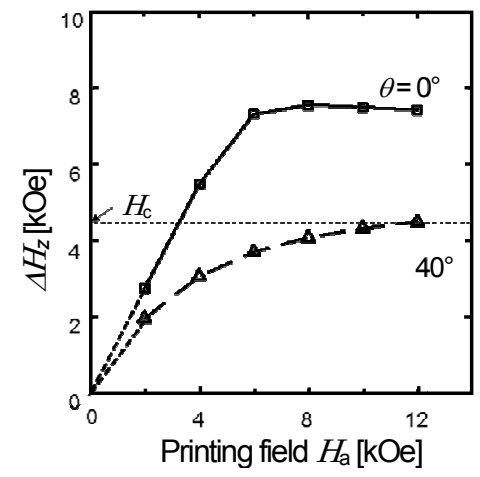

Fig. 10 Dependence of the recording field at the pattern edge on the printing field in edge printing with $\theta=0^{\circ}$ and $\theta=40^{\circ}$.

\section{2 計算結果}

3. 1 節の実験結果を裏付けるために, マイクロマグネティック シミュレーションにより記録層の磁化状態を計算し, 転写された スレーブ媒体からの漏れ磁場を求めた. Fig. 8 に, 有限要素法によ り求めた記録磁場分布を示す. Fig. 8 から, 記録磁場の垂直成分は マスター磁性膜のエッジ部においてピークを持ち，面内成分は磁 性膜の接触部で減少し，非接触部で増加していることがわかる.ま た, マスターパターンを 40 傾斜させると記録磁場の垂直成分は約 1/2 に減少する. これは, マスター磁性膜内部の磁化がパターン方 向に向く傾向にあるためである ${ }^{3)}$

次に, Fig. 8 の記録磁場分布を用いて計算した, スレーブ媒体の 磁化状態及びスレーブ媒体からの漏孔磁場分布を Fig. 9 に示寸. なお, 磁化は $M_{\mathrm{s}}$ で規格化してある. Fig. 9 から, マスターパターン を $40^{\circ}$ 傾斜させても, 記録層における磁化の垂直成分 $M_{Z}$ は，ピー クにおいてはほぼ飽和まで磁化していることがわかる。また， MFM 出力に相当寸ると考えられる, スレーブ媒体からの漏孔磁 場の垂直成分を見ると，6\%程度しか劣化していない. これは, $10 \%$ 程度しか転写特性が劣化しないという実験結果とよく一致してい る.

\section{3 記録磁場面内成分の影響}

マスターパターンを 40 傾斜させると記録磁場の垂直成分は約 $1 / 2$ に減少するが，この垂直成分の減少が転写特性に及ぼす影響は 小さいといえる.この原因は, エッジ転写における強い面内磁場成 分にあるものと思われる. Fig. 8 に示すように, 磁場の垂直磁場成 分の 0-p 值を $\Delta H_{Z}$ とし, Fig. 10 に $\Delta H_{z}$ の転写磁場依存性を示す. 実 験で用いた HD の保磁力は $4.5 \mathrm{kOe}$ であり, Fig. 8 をみると, マス ターパターンを 40 傾けると $\Delta H_{z}$ は保磁力以下に減少することが わかる. 特に, マスターパターン傾斜角 $40^{\circ}$, 転写磁場 $4 \mathrm{kOe}$ の場 合, $\Delta H_{z}$ は約 $3.0 \mathrm{kOe}$ であり, 記録磁場の垂直成分のみを考えたの では，ほとんど磁化反転しないことになる. しかし, Fig. 6 から, 転 写できることが実験的に確忍されている. 以上の結果から, エッジ 転写においては記録磁場の面内成分が磁化反転を促し, 垂直成分 が弱、場合でも転写できるものと推定される。

そこで, エッジ転写において, 記録磁場の面内成分が磁化反転に 及ぼす影響を調べるために，マイクロマグネティックシミュレー ションを行った. マスター磁性膜エッジ部に現れる記録磁場を想 定し, 消磁状態のスレーブ媒体に対して垂直磁場成分のみを印加 した場合，及び面内磁場成分まで含めて印加した場合のそれぞれ について反転磁化分布を求めた. マスターパターン傾斜角 $40^{\circ}$, 転 写磁場 $4 \mathrm{kOe}$ で転写するとき, マスター磁性膜エッジ部分に現れ る記録磁場の垂直成分は約 $3.1 \mathrm{kOe}$, 面内成分は約 $3.9 \mathrm{kOe}$, 面内 成分と垂直成分のベクトル和は約 $5.0 \mathrm{kOe}$ で, 膜面垂直方向と磁 場の成す角を Fig. 11(a)に示す㠶すると, 約 51.9である. 記録層 の磁気特性は 2.2 節の計算と同様の值を用いた.

Fig. 11 にマイクロマグネティックシミュレーションにより得ら れた反転磁化分布を示寸. Fig. 11 の濃淡は, 記録層磁化の垂直成分 $M_{z}$ を飽和磁化 $M_{\mathrm{s}}$ で規格化した值であり，明部が膜面上向き，暗部 が下向きの磁化を示している. Fig. 11(b)はエッジ転写の初期状態 で, AC 消磁状態である. Fig.11(c)は記録磁場の垂直成分のみを考 


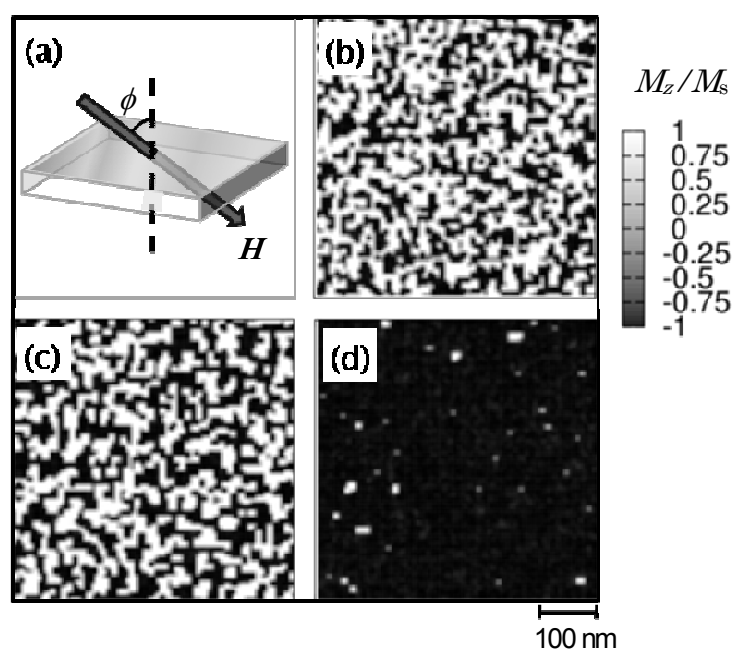

Fig. 11 Calculated magnetization reversal distributions with various fields: (a) calculation model, (b) initial state (ac erase), (c) $H=3.0 \mathrm{kOe}, \phi=0^{\circ}$, and (d) $H=5.0 \mathrm{kOe}, \phi=50^{\circ}$.

慮した場合, Fig. 11(d)は面内成分まで含めた場合の計算結果であ る. Fig. 11(b) 〜 (d)において, 全体の $M_{Z} / M_{\mathrm{s}}$ を平均し, その平均 值を求めるとそれぞれ, $0.00,-0.10,-0.96$ となる. よって, 垂直 磁場成分だけでは $10 \%$ 程度しか磁化反転しないが, 面内磁場成分 を加えることでほぼすべての粒子が磁化反転することがわかる.

ここで, 異方性磁場 $10 \mathrm{kOe}$ の単磁区粒子が Stoner-Wohlfarth モデルに従うと仮定して考察する. このような粒子の集合体では, Fig. 11(c)の計算結果 $\left(\phi=0^{\circ}\right)$ において, 磁場が磁化反転に必要な值 に達していないため, 10\%程度しか反転できない. また, Fig. 11(d) の㕶 50॰の場合, Stoner-Wohlfarth モデルにおいて磁化反転に必 要な磁場は約 $5.5 \mathrm{kOe}$ であることから, ほぼすべての粒子が反転 したと考えられる. 一方, 実験では転写磁場 $H_{\mathrm{a}}$ が $4 \mathrm{kOe}$, マスター パターン傾斜角 $\theta$ $40 \circ$ 条件であれば転写が可能であり(Fig. 6), $4 \mathrm{kOe}$ よりも低い $H_{\mathrm{a}}$ では，いずれの $\theta$ であっても転写が困難であ った. $H_{\mathrm{a}}$ が $4 \mathrm{kOe}, \theta か ゙ ~ 40^{\circ}$ の場合のマスター磁生膜エッジ部近傍に おける記録磁場を計算により求めると, Fig. 11(d)で与えた条件と なる. すなわち, 実験結果は, このような条件のときに磁化が反転 し，それよりも低い磁場の場合には反転しないことを示している. このことは, 最も低い反転磁場が $5 \mathrm{kOe}\left(\phi か ゙ 45^{\circ}\right.$ のと )であること が示される Stoner-Wohlfarth モデルとほぼ一致している.
以上の結果から, 転写時に強い面内磁場成分を有するエッジ転 写においては, 面内磁場成分が磁化反転に大きく影響することが わかった.

\section{4. まとめ}

スレーブ媒体として市販の垂直磁気記録 HD を用い, マスター パターンの傾斜角が転写特性に及ぼす影響について検討した結果, 次のことが明らかになった.

（1）マスターパターンが 40 傾斜しても転写特性は $10 \%$ 程度しか 劣化しない.

（2）ビット長が変わっても, マスターパターンの傾斜が転写特性 に与える影響は小さい!

（3）マスターパターン傾斜角 $40^{\circ}$ では, 記録磁場の垂直成分は約 $1 / 2$ に減少し HD の保磁力より小さくなるが, エッシ転写時の 強い面内磁場成分が磁化反転を促すことで十分に転写できる. 以上より, マスターパターン傾斜角が $40^{\circ}$ でも, サーボ信号とし て十分な品質の転写特性を得ることができるといえる. これは, 磁 気転写が位相サーボ方式にも対応可能であることを示寸ものであ る.

謝辞 本研究の一部は, 新エネルギー・産業技術総合開発機構 (NEDO) 産業技術研究助成事業の支援により行われました. また, 富士フイルム (株)の皆様にご協力, ご議論を頂きました. ここに 深謝致します.

\section{References}

1) M. Nishikawa, S. Wakamatsu, K. Ichikawa, T. Usa, M. Nagao, T. Ishioka, T. Yasunaga, T. Komine and R. Sugita: IEEE Trans. Magn., 42, 2612 (2006).

2) H. Suzuki, H. Komoriya, Y. Nakamura, T. Hirahara, T. Yasunaga, M. Nishikawa, and M. Nagao: IEEE Trans. Magn., 40, 2528 (2004).

3) T. Saito, H. Yasuda, T. Komine, and R. Sugita: J. Magn. Soc. Jpn., 32, 239 (2008).

4) M. Nakazawa, T. Komine, and R. Sugita: J. Magn. Soc. Jpn., 32, 466 (2008).

5) Y. Sakaguchi, T. Murata, T. Komine, and R. Sugita: J. Magn. Soc. Jpn., 32, 221 (2008)

6) K. Tanabe, S. Okami, T. Saito, T. Komine and R. Sugita: Dig. 32nd Annual Conf., Miyagi, 2008, p.140 (The Magn. Soc. Jpn 2008)

\section{8年10月15日受理，2009年01月09日採録}

